\title{
High-resolution land surface modeling utilizing remote sensing parameters and the Noah UCM: a case study in the Los Angeles Basin
}

\author{
P. Vahmani ${ }^{1}$ and T. S. Hogue ${ }^{1,2}$ \\ ${ }^{1}$ University of California, Los Angeles, CA, USA \\ ${ }^{2}$ Colorado School of Mines, Golden, CO, USA \\ Correspondence to: T. S. Hogue (thogue@mines.edu) \\ Received: 27 April 2014 - Published in Hydrol. Earth Syst. Sci. Discuss.: 4 July 2014 \\ Revised: - - Accepted: 25 October - Published: 3 December 2014
}

\begin{abstract}
In the current work we investigate the utility of remote-sensing-based surface parameters in the Noah UCM (urban canopy model) over a highly developed urban area. Landsat and fused Landsat-MODIS data are utilized to generate high-resolution $(30 \mathrm{~m})$ monthly spatial maps of green vegetation fraction (GVF), impervious surface area (ISA), albedo, leaf area index (LAI), and emissivity in the Los Angeles metropolitan area. The gridded remotely sensed parameter data sets are directly substituted for the land-use/lookuptable-based values in the Noah-UCM modeling framework. Model performance in reproducing ET (evapotranspiration) and LST (land surface temperature) fields is evaluated utilizing Landsat-based LST and ET estimates from CIMIS (California Irrigation Management Information System) stations as well as in situ measurements. Our assessment shows that the large deviations between the spatial distributions and seasonal fluctuations of the default and measured parameter sets lead to significant errors in the model predictions of monthly ET fields $\left(\mathrm{RMSE}=22.06 \mathrm{~mm} \mathrm{month}^{-1}\right.$ ). Results indicate that implemented satellite-derived parameter maps, particularly GVF, enhance the capability of the Noah UCM to reproduce observed ET patterns over vegetated areas in the urban domains $\left(\mathrm{RMSE}=11.77 \mathrm{~mm} \mathrm{month}^{-1}\right)$. GVF plays the most significant role in reproducing the observed ET fields, likely due to the interaction with other parameters in the model. Our analysis also shows that remotely sensed GVF and ISA improve the model's capability to predict the LST differences between fully vegetated pixels and highly developed areas.
\end{abstract}

\section{Introduction}

Urbanization introduces significant changes to land surface characteristics that ultimately perturb land-atmosphere fluxes of sensible heat, latent heat, and momentum which, in turn, alter atmospheric properties as well as local weather and climate (Landsberg, 1981; Kalnay and Cai, 2003; Miao et al., 2009; De Ridder et al., 2012). Urban surfaces are covered with variety of materials with distinct thermal, radiative, and moisture properties influencing surface energy and water budgets (Arnfield, 2003). Moreover, contrasting aerodynamic properties of buildings significantly change surface roughness (Cotton and Pielke, 1995). The effects associated with modified urban landscapes extend to air quality (Taha et al., 1997), local temperatures (Bornstein, 1987; Van Wevenberg et al., 2008), local and regional atmospheric circulation (Pielke et al., 2002; Marshall et al., 2004; Niyogi et al., 2006), and regional precipitation patterns (Changnon and Huff, 1986; Changnon, 1992; Lowry, 1998).

Mesoscale meteorological models have been increasingly applied over urban areas to examine the urban-atmosphere exchange of heat, moisture, momentum, or pollutants. Recently updated parameterization in the community Weather Research and Forecasting (WRF) model includes coupling between the Noah LSM (land surface model) and a singlelayer urban canopy model (UCM; Kusaka et al. 2001; Kusaka and Kimura, 2004), which has substantially advanced the understanding and modeling of the mesoscale impact of cities. The coupled WRF-Noah UCM has been applied to major metropolitan regions around the world (e.g., Houston, Beijing, Guangzhou/Hong Kong, Salt Lake City, 
and Athens) to better understand the contribution of urbanization to changes in urban heat island, surface ozone, horizontal convective rolls, boundary layer structure, contaminant transport and dispersion, and heat wave events (Chen et al., 2004; Jiang et al., 2008; Miao and Chen, 2008; Miao et al., 2009; Wang et al., 2009; Tewari et al., 2010; Wei-guang et al., 2011; Giannaros et al., 2013). A common concern with the use of these complex mesoscale models, however, is the high level of uncertainty in the specification of surface cover and geometric parameters (Loridan et al., 2010; Chen et al., 2011). Although realistic representation of surface properties is critical for accurate simulation of the physical processes occurring in urban regions, the majority of previous modeling studies rely on traditional land use data and lookup tables to define surface parameters.

Remotely sensed observations provide important spatial information on urban-induced physical modifications to the Earth's surface (Jin and Shepherd, 2005). Airborne lidar (light detection and ranging) systems and photogrammetric techniques have been utilized to produce morphological parameters over urban areas (Burian et al., 2004, 2006, 2007; Taha, 2008; Ching et al., 2009). Burian et al. (2004) used airborne lidar data, at $1 \mathrm{~m}$ resolution, to generate data sets of 20 urban canopy parameters (e.g., building height, height-towidth ratio, and roughness length) for an air quality modeling study over Houston, Texas. Taha (2008) introduced an alternative and low-cost approach for generating urban canopy parameters input for the uMM5 over Sacramento region, California. The study relied on commercially available Google Earth Pro imagery to generate urban geometry parameters (e.g., pavement land-cover fraction, roof cover fraction, and mean building height). Using lidar-based three-dimensional data sets of buildings and vegetation, Ching et al. (2009) presented a high-resolution database of the geometry, density, material, and roughness properties of the morphological features for applications in WRF and other models over Houston, Texas. While promising, the availability of such data sets is currently limited to a few geographical locations and the reproduction of such data sets is extremely challenging due to high collection costs and data management difficulties associated with the extremely large size of lidar data sets (Burian et al., 2006; Ching et al., 2009).

Observations from satellites, on the other hand, have been utilized in model validation processes over urban areas (Miao et al., 2009; Giannaros et al, 2013). In addition to in situ observations, Giannaros et al. (2013) included MODIS (Moderate Resolution Imaging Spectroradiometer)-based land surface temperature (LST) products in their modeling study of the urban heat island (UHI) over Athens, Greece. Similarly, Miao et al. (2009) utilized $1 \mathrm{~km}$-resolution MODIS data to verify the WRF-Noah-UCM-simulated LST distribution in Beijing. Other studies have employed satellite data to replace outdated urban land use maps in atmospheric models with new remote sensing products (Cheng and Byun, 2008; Cheng et al., 2013). Focusing on boundary layer mixing conditions and local wind patterns in the Houston Ship Channel, Cheng and Byun (2008) reported that the Noah LSM and planetary boundary layer (PBL) scheme performances in the MM5 were improved when land-use-type distributions were correctly represented in the model using high-resolution Landsat-based land use data. Cheng et al. (2013) compared WRF simulations in the Taiwan area using US Geological Survey (USGS)-, MODIS-, and SPOT (Système Pour l'Observation de la Terre)-based land use data. Using the new high-resolution land use types obtained from SPOT satellite imagery, the WRF predictions of daytime temperatures and onshore sea breezes had the best agreement with observed data. Furthermore, more accurate surface wind speeds were simulated when MODIS and SPOT data replaced conventional USGS land use maps in the WRF runs due to the more realistic representation of roughness length in the remotely sensed databases. Although these and other previous studies (e.g., Jin and Shepherd, 2005) have recognized the usefulness of satellite imagery (e.g., NASA's Terra, Aqua, and Landsat data) in specifying surface physical characteristics in urban environments, very few have directly incorporated highresolution gridded satellite-based parameters (e.g., impervious surface area, albedo, and emissivity) into parameter estimation within land surface/atmospheric modeling systems.

In the current work we investigate the utility of remotesensing-based surface parameters in the Noah-UCM modeling framework over a highly developed urban area. Among parameters that can be related to a measurable physical quantity, we evaluate those routinely and freely obtained from satellite-based platforms. The derived parameter sets are implemented in the Noah UCM with a focus on simulated surface energy and water cycles that are essential feedback to the widely used WRF model. Landsat and fused LandsatMODIS data are utilized to generate high-resolution $(30 \mathrm{~m})$ monthly spatial maps of green vegetation fraction (GVF), impervious surface area (ISA), albedo, leaf area index (LAI), and emissivity in the Los Angeles metropolitan area. The temporal and spatial distributions of newly assigned parameters are compared with those based on the model lookup tables. Next, gridded remotely sensed parameter data sets are directly incorporated into the Noah-UCM modeling framework replacing the land-use/lookup-table-based values. The sensitivity of the simulated energy and water fluxes to the newly developed spatial metrics of parameters is presented. The model's performance in reproducing evapotranspiration (ET) and LST fields is evaluated utilizing Landsat-based land surface temperature and ET estimates from CIMIS (California Irrigation Management Information System) stations as well as in situ measurements. Finally, the influence of each parameter set on the urban energy and water budgets is investigated. 


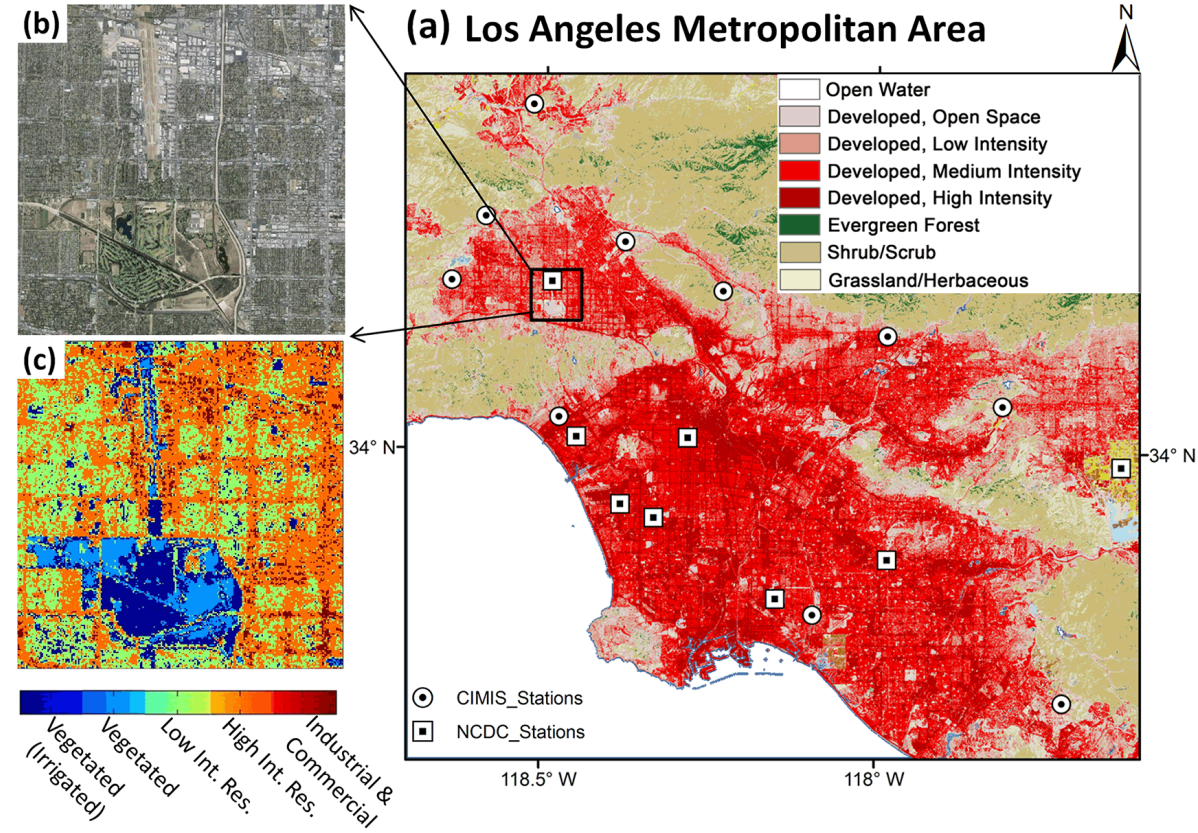

Figure 1. (a) NOAA C-CAP land cover map of the Los Angeles metropolitan area including study domain, 10 CIMIS stations (white circles), and 8 NCDC stations (white squares); (b) Google image of the study domain; and (c) the Noah-UCM urban land cover classification of the study domain.

\section{Study area}

The study domain is a $49 \mathrm{~km}^{2}$ highly developed neighborhood in the city of Los Angeles (Fig. 1). Los Angeles is the second most populous city in the United States with a population of 3.8 million (US Census, 2011), covering an area of $1215 \mathrm{~km}^{2}$ in southern California. The city has a Mediterranean climate and receives $381 \mathrm{~mm}$ of annual precipitation, mostly over the winter months (NOAA-CSC, 2003; SCDWR, 2009). Due to the semiarid nature of the region, the city's water supply is heavily dependent on imported water $52 \%$ from the Colorado River and $36 \%$ from the Los Angeles Aqueduct (Los Angeles Department of Water and Power (LADWP), 2010). Regional water demands and the extensive dependence on external sources make accurate spatial representation of the metropolitan area in regional land surface/atmospheric models imperative for predicting current and future water budgets. The study domain includes commercial/industrial as well as low- and high-intensity residential land cover types and a large park with both irrigated and nonirrigated landscapes (Fig. $1 \mathrm{~b}$ and c).

\section{Remotely sensed parameters}

Remote sensing data are retrieved from Landsat ETM+ images with a nominal pixel resolution of $30 \mathrm{~m}$ in the shortwave bands and $60 \mathrm{~m}$ in the thermal band. The level $1 \mathrm{GtETM}+$ imagery from USGS EROS, spanning years 2010-2011, are calibrated and atmospherically corrected through the
Landsat Ecosystem Disturbance Adaptive Processing System (LEDAPS). Study domain data are not affected by the failure of the Landsat-7 ETM+ Scan Line Corrector in 2003 (SLCoff). Using a knowledge-based approach, similar to the one introduced by Song and Civco (2002), several binary masks are applied to the images to detect contaminated areas (cloud and shadow). Images with cloud and/or shadow are distinguished and omitted in the following parameter retrievals. A total of 24 pure images, acquired over 2 years, are utilized in the parameter estimation processes.

In addition to Landsat observations, MODIS products from Terra and Aqua satellite platforms are also utilized. The MODIS MCD43A BRDF (bidirectional reflectance distribution function) products, concurrent with pure Landsat images, are collected for use in the parameter calculations. The $500 \mathrm{~m}$ BRDF products are generated by the MODIS Adaptive Processing System (MODAPS) at the Goddard Space Flight Center (GSFC), using a kernel-driven linear model, and distributed through the Land Processes DAAC (Distributed Active Archive Center; Justice et al., 2002; Schaaf et al., 2002; Shuai et al., 2008). The described Landsat and MODIS-based data are used to produce a group of six remotely sensed derivatives, as follows.

\section{Green vegetation fraction (GVF)}

GVF spatial maps are derived according to Gutman and Ignatov (1998) utilizing NDVI (normalized difference vegetation index) measurements. First, atmospherically corrected 
reflectance values from the red $\left(\rho_{\mathrm{ETM}}\right)$ and near-infrared ( $\left.\rho_{\text {ETM }}\right)$ bands of Landsat ETM + are used to derive NDVI maps for each date of imagery based on Eq. (1). Next, assuming the vegetated part of a pixel is covered by dense vegetation (i.e., it has a high LAI), GVF is calculated using Eq. (2).

$\mathrm{NDVI}=\frac{\rho_{\mathrm{ETM} 4}-\rho_{\mathrm{ETM} 3}}{\rho_{\mathrm{ETM} 4}+\rho_{\mathrm{ETM} 3}}$,

$\mathrm{GVF}=\frac{\mathrm{NDVI}-\mathrm{NDVI}_{\mathrm{o}}}{\mathrm{NDVI}_{\infty}-\mathrm{NDVI}_{\mathrm{o}}}$,

where $\mathrm{NDVI}_{\mathrm{o}}$ and $\mathrm{NDVI}_{\infty}$ are constant values computed using signals from bare soil and densely vegetated pixels in the study domain, respectively.

\section{Impervious surface area (ISA)}

ISA is shown to be inversely proportional to vegetation fraction where non-vegetated pervious surfaces are rare (Bauer et al., 2007). Since the majority of pervious surfaces in the studied domain are vegetated and heavily irrigated throughout the year, ISA is assumed to be the complement of the vegetation fraction:

$\mathrm{ISA}=\left(1-\mathrm{GVF}_{\max }\right) \cdot 100$,

where $\mathrm{GVF}_{\text {max }}$ is the maximum GVF detected over the 2year study period. The produced ISA map shows high accuracy $(>95 \%)$ when compared to a previously developed high-resolution land cover map, based on QuickBird remote sensing data, aerial photographs, and geographic information systems over the city of Los Angeles (McPherson et al., 2008). We speculate that one cause that may contribute to the high accuracy of this assumption is that ISA overestimation, induced by non-vegetated pervious surfaces, is offset by tree canopies that cover areas larger than underlying pervious surfaces.

\section{Albedo}

With a recent methodology by Shuai et al. (2011) employed, $30 \mathrm{~m}$ land surface albedo maps are generated utilizing Landsat surface reflectance and anisotropy information from concurrent $500 \mathrm{~m}$ MODIS BRDF products. Landsat data are reprojected from UTM to MODIS sinusoidal projection and aggregated from 30 to $500 \mathrm{~m}$. Using USGS-based land cover types, the percentage of each land cover class within each MODIS pixel is computed, then relatively pure pixels (> 85\% purity) are selected for each class. MCD43A2 quality assessment product is used to choose highest-quality MODIS MCD43A1 BRDF parameters for the pure pixels. The concurrent parameters are used to calculate nadir reflectance, white-sky albedo, and black-sky albedo under the solar geometry at Landsat overpass time and MODIS scale. Next, the spectral albedo-to-nadir reflectance ratios, for white-sky and black-sky albedos, are calculated over the pure pixels. The resultant ratios, specific to each land cover class, are applied to Landsat surface reflectance to generate the spectral white-sky and black-sky albedos for each Landsat pixel. A further narrowband-to-broadband conversion based on extensive radiative transfer simulations by Liang (2000) is applied to generate the broadband albedos in a shortwave regime. Finally, albedo (blue sky) is modeled as an interpolation between the black-sky $\left(\alpha_{\mathrm{bs}}\right)$ and whitesky $\left(\alpha_{\mathrm{ws}}\right)$ albedos as a function of the fraction of diffuse skylight $(\mathrm{S}(\theta, \tau(\lambda))$ which is estimated by the $6 \mathrm{~S}$ (Second Simulation of the Satellite Signal in the Solar Spectrum) codebase (Eq. 4; Schaaf et al., 2002).

$\propto(\theta, \lambda)=\{1-\mathrm{S}(\theta, \tau(\lambda))\} \alpha_{\mathrm{bs}}(\theta, \lambda)+S(\theta, \tau(\lambda)) \alpha_{\mathrm{ws}}(\theta \lambda)$,

where $\tau, \theta$, and $\lambda$ are optical depth, solar zenith, and wavelength, respectively.

\section{Leaf area index (LAI)}

Stenberg et al. (2004) showed that a reduced simple ratio (RSR) explains $63-75 \%$ of the variations in LAI and that maps of projected LAI, based on RSR, have good agreement with observations. In the current study, LAI values are retrieved based on the LAI-RSR correlations, which are specified utilizing table-based LAI estimates in pure (fully vegetated) pixels and remotely sensed RSR maps. The atmospherically corrected reflectance values of Landsat ETM spectral channels red $\left(\rho_{\mathrm{ETM}}\right)$, near infrared $\left(\rho_{\mathrm{ETM}}\right)$, and midinfrared $\left(\rho_{\text {ETM } 5}\right)$, implemented in the following Eq. $(5)$, define RSR:

$\mathrm{RSR}=\frac{\rho_{\mathrm{ETM}} 4}{\rho_{\mathrm{ETM} 3}} \frac{\rho 5_{\max }-\rho_{\mathrm{ETM}} 5}{\rho_{5_{\max }}+\rho_{5_{\min }}}$,

where $\rho_{\text {ETM5min }}$ and $\rho_{\text {ETM5max }}$ are the smallest and largest mid-infrared reflectance detected in the Landsat ETM images over the study domain, excluding open water pixels.

\section{Emissivity}

Among various methods developed to define land surface emissivity, the NDVI thresholds method (NDVI ${ }^{\mathrm{THM}}$ ) has been widely applied to urban areas (Stathopoulou and Cartalis, 2007; Stathopoulou et al., 2007; Tan and Li, 2013). $\mathrm{NDVI}^{\mathrm{THM}}$ is superior to other methods since the consideration of the internal reflections (cavity effects), caused by heterogeneous surfaces minimizes the overall error in this approach (Sobrino et al., 2001). This methodology, originally introduced by Sobrino and Raissouni (2000) and modified later by Stathopoulou et al. (2007) for urban areas, is selected for land surface emissivity estimation in the current work. Using the Landsat-based NDVI thresholds, the study area is divided into four classes: (1) fully vegetated (NDVI >0.5), (2) built-up areas with sparse vegetation (NDVI $\leq 0.2)$, (3) a 
mixture of man-made material and vegetation (NDVI $>0.2$ and $\leq 0.5$ ), and (4) water bodies (NDVI <0). Mean emissivity values of $0.980,0.920$, and 0.995 are then used for fully vegetated, built-up, and water pixels (Similar to Tan and Li, 2013). Emissivity values ( $\varepsilon$ ) for mixed pixels (class 3 ) are estimated using the following equations (for details see Stathopoulou et al., 2007):

$\varepsilon=0.017 P_{V}+0.963$,

$P_{V}=\frac{(\mathrm{NDVI}-0.2)^{2}}{(0.5-0.2)^{2}}$.

\section{Land surface temperature (LST)}

The emissivity-corrected land surface temperature (LST) is calculated as follows (Artis and Carnahan, 1982):

$\mathrm{LST}=\frac{\mathrm{BT}}{\left\{1+\left[\frac{\lambda \cdot \mathrm{BT}}{\rho} \cdot \ln \varepsilon\right]\right\}}$,

where BT is Landsat at sensor brightness temperature $(\mathrm{K}), \lambda$ and $\varepsilon$ are the wavelength of emitted radiance $(11.5 \mu \mathrm{m})$ and surface emissivity, and $\rho=\mathrm{hc} / \sigma\left(1.438 \times 10^{-2} \mathrm{~m} \mathrm{~K}\right)$, where $\sigma, \mathrm{h}$, and c are Boltzmann constant, Planck's constant, and the velocity of light, respectively.

\section{Numerical modeling system}

\subsection{Noah LSM-UCM model}

Land surface processes are parameterized using the offline Noah LSM (Chen and Dudhia, 2001) coupled with the single-layer UCM (Kusaka et al. 2001; Kusaka and Kimura, 2004). The Noah LSM is based on a diurnally dependant Penman potential evaporation approach, a multilayer soil parameterization, a canopy resistance model, surface hydrology, and frozen ground physics (Chen et al., 1996, 1997; Chen and Dudhia, 2001; Ek et al., 2003). The UCM parameterization includes urban building geometry, shadowing from buildings, reflections and trapping of radiation in a street canyon, and an exponential wind profile. The Noah LSM provides surface sensible and latent heat fluxes and surface skin temperature for vegetated areas (e.g., parks and trees), and the UCM calculates the fluxes for impervious surfaces. The outputs from the Noah LSM and UCM are coupled through the urban surface fractions.

\subsection{Irrigation module}

Irrigation is accounted for in the Noah-UCM modeling framework by incorporating an urban irrigation module developed in our previous work (Vahmani and Hogue, 2013, 2014). The developed irrigation scheme mimics the effects of urban irrigation by increasing soil moisture content in vegetated portion of grid pixels at a selected interval. Added anthropogenic soil moisture contribution is a function of the soil moisture deficit, which is the difference between irrigated soil moisture content and actual soil moisture content in the top soil layer. The irrigation module calculates irrigated soil moisture content $\left(\mathrm{SMC}_{\mathrm{IRR}} ; \mathrm{m}^{3} \mathrm{~m}^{-3}\right)$, soil moisture deficit (DEF; $\mathrm{m}^{3} \mathrm{~m}^{-3}$ ), and irrigation water (IRR; $\left.\mathrm{kg} \mathrm{m}^{-2} \mathrm{~s}^{-1}\right)$ as

$\mathrm{SMC}_{\mathrm{IRR}}=\alpha \mathrm{SMC}_{\max }$,

$\mathrm{DEF}=\max \left\{\left[\mathrm{SMC}_{\mathrm{IRR}}-\mathrm{SMC}_{1}\right], 0\right\}$,

$\mathrm{IRR}=\frac{\rho_{\mathrm{w}}}{\Delta t} \mathrm{DEFD}_{1}$,

where the saturation soil moisture content $\left(\mathrm{SMC}_{\mathrm{max}} ; \mathrm{m}^{3} \mathrm{~m}^{-3}\right)$ and irrigation demand factor $(\alpha$; unitless) define irrigated soil moisture content (Eq. 9); and $\mathrm{D}_{1}$ is top soil layer thickness $(10 \mathrm{~cm}) ; \rho_{\mathrm{w}}\left(\mathrm{kg} \mathrm{m}^{-3}\right)$ and $\Delta t$ stand for water density and Noah-UCM time step (3600 s), respectively. The parameter $\alpha$, ranging from zero to one, regulates the amount of irrigation water added to the soil each time the scheme increases the soil moisture, simulating an irrigation event. Similar to previous studies (Hanasaki et al. 2008a, b; Pokhrel et al. 2012) an irrigation demand factor of 0.75 is utilized in the current work. The irrigation interval is set to three times per week according to the water restrictions implemented by LADWP in 2010.

\subsection{Improving the UCM-simulated LST}

The calculation of the impervious surface temperature in the UCM version used in this study has been shown to be inaccurate ( $\mathrm{Li}$ and Bou-Zeid, 2014). This is due to the fact that the turbulent transfer coefficient $\left(C_{\mathrm{h}}\right)$ for the whole pixel is calculated using only momentum and thermal roughness lengths of vegetated portion, ignoring the developed surface impact on $C_{\mathrm{h}}$. Li and Bou-Zeid (2014) showed that this inconsistency could result in large biases in simulated LST values. In the current study, an alternative LST calculation, proposed by Li and Bou-Zeid (2014), is used as follows. First, a revised surface temperature of the impervious part of the pixel $\left(\mathrm{T}_{\mathrm{S}}\right)$ is calculated based on canyon temperature $\left(\mathrm{T}_{\mathrm{c}}\right)$ and roof surface temperature $\left(\mathrm{T}_{r}\right)$ :

$T_{\mathrm{s}}=f_{\mathrm{r}} \times T_{\mathrm{r}}+\left(1-f_{\mathrm{r}}\right) \times T_{\mathrm{c}}$,

where $f_{\mathrm{r}}$ is the roof fraction of the impervious surface. Note that the $T_{\mathrm{c}}$ calculated by the UCM is an equivalent aerodynamic surface temperature aggregated for canyon surfaces, including walls and roads. Next, the LST for the whole grid cell is computed as a weighted average based on the $T_{\mathrm{s}}$ and surface temperature of pervious part $\left(T_{1}\right)$ :

$\mathrm{LST}=f_{\mathrm{urb}} \times T_{\mathrm{s}}+\left(1-f_{\mathrm{urb}}\right) \times T_{1}$,

where $f_{\text {urb }}$ is the urban fraction of the pixel.

\subsection{Land cover data and forcing fields}

The Noah-UCM modeling system requires static data to describe physical characteristics of the surface, including soil 
Table 1. Model scenarios (1-9) and the incorporated remotely sensed parameter sets.

\begin{tabular}{lccccc}
\hline & GVF & ISA & Albedo & LAI & Emissivity \\
\hline Scenario 1 (def. par.) & - & - & - & - & - \\
Scenario 2 (R.S. GVF) & X & - & - & - & - \\
Scenario 3 (R.S. ISA) & - & X & - & - & - \\
Scenario 4 (R.S. albedo) & - & - & X & - & - \\
Scenario 5 (R.S. LAI) & - & - & - & X & - \\
Scenario 6 (R.S. emissivity) & - & - & - & - & X \\
Scenario 7 (R.S. par. group 1) & X & X & - & - & - \\
Scenario 8 (R.S. par. group 2) & - & - & X & X & X \\
Scenario 9 (R.S. par. all) & X & X & X & X & X \\
\hline
\end{tabular}

type, slope type, vegetation type, and urban type. A combination of the Soil Data Mart (http://sdmdataaccess.nrcs. usda.gov/) and the Los Angeles Department of Public Works (LADPW) databases are used to gather soil classification information. Land use and land cover are parameterized using the $30 \mathrm{~m}$ NOAA C-CAP-2006 land cover data which is transformed to urban and vegetation type spatial maps over the study domain. High-, medium-, and low-intensity developed land cover types, recognized by NOAA, are converted to UCM industrial/commercial, high-intensity, and low-intensity residential types, respectively. The developed open space, along with natural land types, is categorized as 1 of the 27 Noah LSM vegetation classes.

The offline Noah LSM-UCM is forced utilizing hourly ground-based observations from CIMIS and National Climatic Data Center (NCDC) stations for the period from 1 January 2010 to 31 December 2011. There are 10 CIMIS and 8 NCDC stations within close proximity of the study domain (Fig. 1a). The NCDC stations, which use Automated Surface Observing Systems (ASOS), are located at smaller local airports (six stations), one major airport (Los Angeles International Airport), and a university campus (University of Southern California, USC) within the Los Angeles metropolitan area. Reporting the meteorological conditions, the NCDC stations are used for wind speed, air temperature, relative humidity, air pressure, and incoming longwave radiation. All NCDC data are gathered at a standard reference height of $2 \mathrm{~m}$. The regional CIMIS stations are utilized for solar radiation (using LI200S pyranometer) and tipping bucket rain gauges in 18 stations (NCDC and CIMIS) are included in collection of precipitation data. Inverse-distance weighting (second power) is employed to create the spatially gridded forcing fields. Linear interpolation and data from the nearest gage are utilized to replace missing data.

\section{Numerical experiments and evaluation methods}

\subsection{Remote-sensing-based parameterization}

To investigate the sensitivity of the Noah-UCM model to integration of the developed remotely sensed parameters, nine simulation scenarios are designed (Table 1). A control experiment (scenario 1) is conducted in which all default parameters are utilized in the Noah UCM. Scenarios 2 to 6 explicitly assess each individual parameter effects on urban energy and water budgets using the newly incorporated remote sensing parameters. Scenario 7 analyzes the effects of employing both remotely sensed GVF and ISA, while scenario 8 assesses simultaneous integration of albedo, LAI, and emissivity. We are interested in the comparison of scenarios 7 and 8 as the Noah-UCM parameterizations use GVF and ISA to select albedo, LAI, emissivity, and roughness length values from the predefined ranges in the parameter tables. It is worth mentioning that GVF alters the roughness length values over pervious or natural areas. However, roughness length and building height over the impervious surfaces are kept at the default values listed by Chen et al. (2011). scenarios 7 and 8 help quantify the contribution of each parameter group to the model's ability to reproduce the observed surface states and fluxes. Finally, the last experiment (scenario 9) implements all five remotely sensed parameter sets in the simulations. It should be noted that the GVF and LAI measurements over mixed pixels (vegetated urban areas) are scaled up by multiplying the remotely sensed values by $1 /(1-$ urban fraction) since in the Noah-UCM modeling framework these parameters characterize only the pervious portion (1-urban fraction) of each pixel. However, remotely sensed albedo and emissivity values over each pixel are assigned to both pervious and impervious surfaces for that pixel. Other than the implemented remote-sensing-based parameters, the rest of the model parameters are kept at default values. All experiments incorporate the irrigation module and irrigation rates are kept constant in all scenarios. All scenarios are run at $30 \mathrm{~m}$ spatial and $1 \mathrm{~h}$ temporal resolutions, spanning 2010 and 2011, with the first 3 months used as model initialization. 


\subsection{Model evaluation approach}

In order to evaluate the performance of the Noah-UCM modeling framework, simulated LSTs are compared with concurrent Landsat observations and simulated latent heat flux time series are assessed against CIMIS-based ET observations. The CIMIS network was established in 1982 by the CDWR (California Department of Water Resources) and the University of California at Davis in order to provide real-time weather conditions and irrigation water need estimates for California's agricultural community. The automated CIMIS stations measure hourly surface solar radiation, temperature, humidity, wind, precipitation, soil temperature, and surface pressure (http://wwwcimis.water.ca.gov). The reference ET $\left(\mathrm{ET}_{0}\right)$ is calculated for each site, utilizing observed meteorological fields over a well-watered soil. Utilizing a methodology introduced by CDWR (2000), actual urban landscape ET is estimated using $\mathrm{ET}_{0}$ and a landscape coefficient, which is a function of species, density, and microclimate factors. Based on the authors' knowledge in the study landscape as well as a report by CDWR (2000), we assume "moderate" (trees and shrubs) and "high" (turf grass) water needs. Following the CDWR (2000) instructions on irrigation zones with mixed water need categories (i.e., low, moderate, and high), a value from the high category is selected (average species factor $=0.80$ ). Assuming the "average" category for vegetation density, a density factor of 1 is used. Furthermore, a "high" category of microclimate condition is used (microclimate factor $=1.25$ ) for the current highly developed study domain. This factor is utilized to take into account the contribution of the developed surfaces to the water loss from vegetated areas, through anthropogenic heating, reflected light, and high temperatures of surrounding heat-absorbing surfaces (e.g., paving and buildings). Using these factors, a landscape coefficient of 1 (landscape coefficient $=$ species factor $\times$ density factor $\times$ microclimate factor) is prescribed. This coefficient and $\mathrm{ET}_{0}$ estimations from 10 CIMIS stations within close proximity of the study domain (Fig. 1a) are utilized to compute the urban landscape ET. Inverse-distance weighting (second power) is employed to create spatially gridded ET maps over fully vegetated pixels in the study area which are then used in validation processes of the Noah UCM. ET output of the model is also evaluated against recent ET measurements in the greater Los Angeles area (Moering, 2011). Moering (2011) employed a previously developed chamber approach to measure instantaneous ET in an irrigated and a nonirrigated park in the Los Angeles metropolitan area during WY (water year) 2011 (WY is defined as 1 October of the previous year to 30 September of the designated year). They reported an annual ET of about $1224 \mathrm{~mm}$ over the observed irrigated park, which is located within our study domain.

\section{Sensitivity study of surface parameter}

\subsection{Temporal evaluation}

The monthly time series of the default Noah UCM and remote-sensing-based GVF, ISA, albedo, and LAI are compared and modeled cumulative monthly sensible and latent heat fluxes, using default and newly estimated parameters, are presented over fully vegetated, low-intensity residential, and industrial/commercial areas (Fig. 2). Fluxes from highintensity residential areas are not presented as they behave similarly to those from the industrial/commercial areas. Except for the summer months, GVF values are significantly increased throughout the year when remote sensing products are utilized (Fig. 2a). Moreover, the default seasonal variations of GVF values, assumed over all the land cover types, are not detected in Landsat imagery (Fig. 2a). The reason for this is the significant and year-round irrigation in the Los Angeles area, which is not accounted for in the default parameter tables. This is confirmed by previous studies (Johnson and Belitz, 2012) that reported urban vegetation supported by water delivery, in contrast to common seasonal behavior of greening in the winter/spring and browning in the summer, maintains constant greenness, which is reflected in NDVI and GVF estimates. GVF plays a dominant role in the Noah-UCM simulations as it defines the vegetated fraction of the natural areas, and specifies albedo, LAI, emissivity, and roughness length values from the predefined ranges in the model lookup tables. Furthermore, GVF partitions the total ET between soil direct and canopy ET. The simulated latent heat flux is considerably decreased (up to $139 \mathrm{MJ} \mathrm{m}^{-2}$ month $^{-1}$ ) in the summertime and increased over the remaining months, when remotely sensed GVF is incorporated in the fully vegetated areas (Fig. 2b). Since any increase of latent heat flux that does not alter the radiative balance leads to a reduction in sensible flux, the newly developed GVF values, in turn, cause enhancements (up to $103 \mathrm{MJ} \mathrm{m}^{-2}$ month $^{-1}$ ) in the simulated summer sensible heat fluxes and a reduction in the sensible heat fluxes during the remaining months (Fig. 2b). Latent and sensible heat fluxes from the low-intensity residential pixels show similar but less significant changes (up to 66.1 and $31.0 \mathrm{MJ} \mathrm{m}^{-2}$ month $^{-1}$, respectively) when the new parameter sets are implemented. Adding remotely sensed GVF causes insignificant changes in the industrial/commercial area fluxes due to the small percentage of vegetated land cover in such areas (Fig. 2d).

There are also large deviations between the lookup-tablebased ISAs and the remotely sensed values. Averaged ISA is decreased $(10 \%)$ over industrial and commercial pixels and increased (49\%) over low-intensity residential areas when remote sensing products are utilized in the parameter estimation process (Fig. 2e). These changes in the impervious surface area, or urban fraction values, have significant effects on monthly latent and sensible heat fluxes over the developed pixels (Fig. 2g and h), due to the critical role 

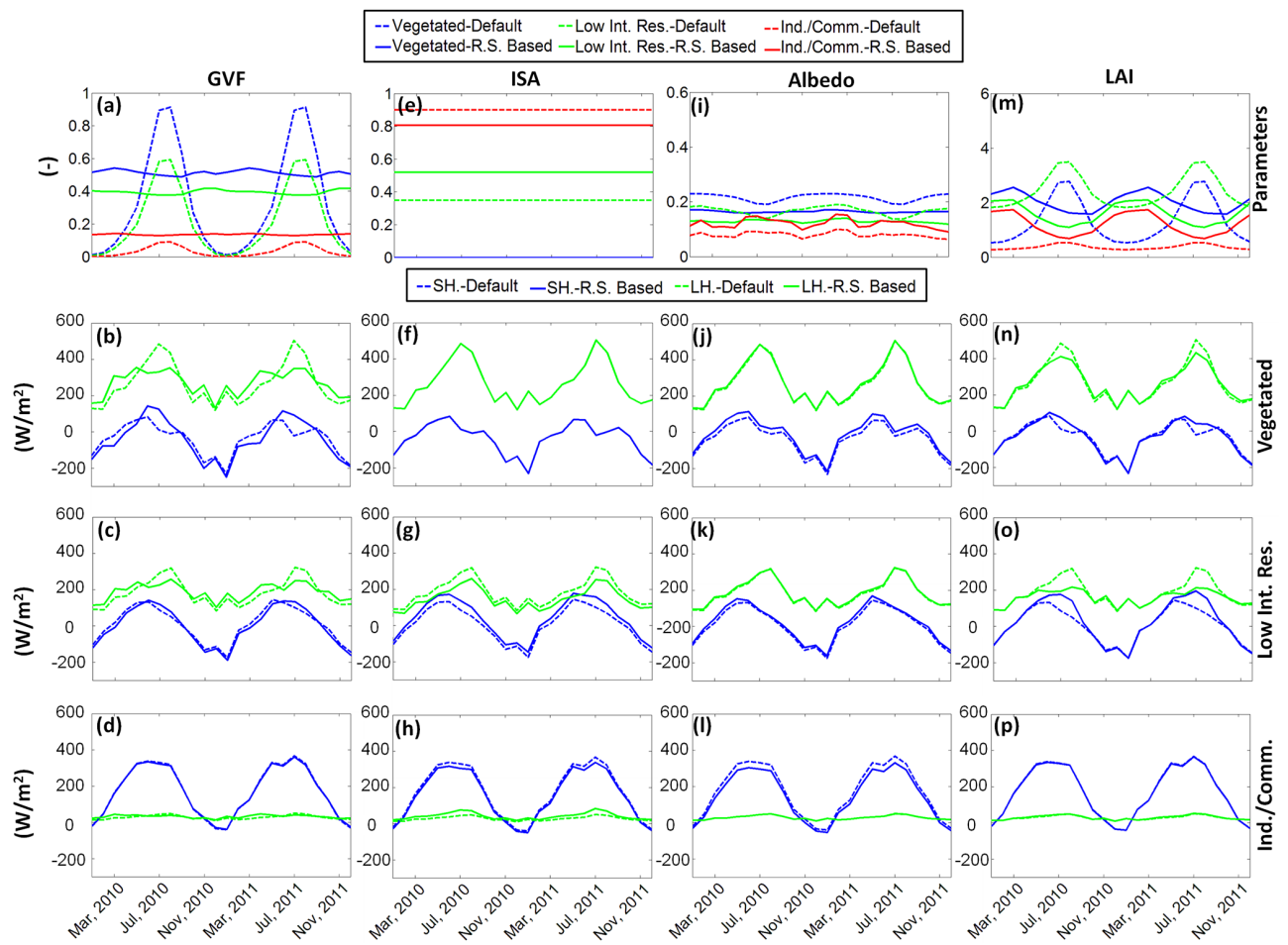

Figure 2. Monthly time series of default Noah UCM compared with remote-sensing-based GVF, ISA, albedo, and LAI (row 1), as well as modeled cumulative monthly sensible and latent heat fluxes $\left(\mathrm{MJ} \mathrm{m}^{-2}\right.$ ) over fully vegetated (row 2), low-intensity residential (row 3), and industrial/commercial areas (row 4) using the default and newly estimated parameters: (b-d) GVF, (f-h) ISA, (j-l) albedo, and (n-p) LAI.

of urban fraction in partitioning of the energy fluxes. Over the low-intensity residential areas, higher ISA values minimize the effects of urban vegetation, which leads to latent heat fluxes decreases (up to $62.6 \mathrm{MJ} \mathrm{m}^{-2} \mathrm{month}^{-1}$ ) and sensible heat fluxes increases (up to $52.4 \mathrm{MJ} \mathrm{m}^{-2}$ month $^{-1}$ ), throughout the year, when remotely sensed data replace default urban fractions (Fig. 2g). These changes are reversed and less significant over the industrial and commercial pixels (maximum latent and sensible heat flux changes of 30.0 and $26.5 \mathrm{MJ} \mathrm{m}^{-2}$ month $^{-1}$, respectively; Fig. $2 \mathrm{~h}$ ). ISA has no influence on the fluxes from fully vegetated pixels which do not include impervious areas (Fig. 2f).

Considerable changes in the monthly albedo averages are detected when incorporating remote sensing data in the parameterization process (Fig. 2i). With the use of fused Landsat and MODIS products, a reduction of averaged albedo values is observed over the fully vegetated and residential areas (up to 48 and $39 \%$, respectively; Fig. 2i). Moreover, the default seasonal variations are hardly noticeable in the remote-sensing-based albedo values, which is due to the consistent greenness in the study area from irrigation throughout the year. On the other hand, considerable albedo increases (up to $39 \%$ ) are detectable over the industrial/commercial pixels (Fig. 2i), which are caused by bright and highly reflective materials seen mainly over the rooftops of industrial/commercial buildings. Albedo affects the radiative energy budget and consequently available energy for the turbulent fluxes. In the current study, decreased albedo values over the fully vegetated and lowintensity residential areas result in reduced loss of solar and longwave radiation, respectively, and, in turn, increases the sensible heat flux (up to 33.8 and $21.5 \mathrm{MJ} \mathrm{m}^{-2}$ month $^{-1}$; Fig. $2 \mathrm{j}$ and $\mathrm{k}$ ). Albedo-induced sensible heat deceases over industrial/commercial pixels are also noticeable (up to 33.9 $\mathrm{MJ} \mathrm{m}^{-2}$ month $^{-1}$; Fig. 21).

Distinct seasonal fluctuations of LAI are observed in the remotely sensed data and the default parameter tables (Fig. $2 \mathrm{~m}$ ). This reflects the fact that landscape plantings are quite different from agricultural crops due to their being composed of collections of vegetation species and affected by complex irrigation patterns which are not taken into account in the vegetation parameter tables in the Noah LSM (CDWR, 2000; Vahmani and Hogue, 2013, 2014). Over the heavily vegetated pixels, the default pattern is reversed in the measured parameter sets, with less seasonal variations and peaks in the wintertime, due to the fact that most of the precipitation occurs in the winter months, over the current study domain (Fig. 2m). The industrial and commercial pixels illustrate higher LAI values in the remotely sensed parameter maps, year-round, when compared to the default values (Fig. 2m). LAI is a critical parameter in the Noah LSM, which is involved in the parameterization 
of the canopy resistance, controlling canopy ET rates. In the presented results (Fig. $2 \mathrm{n}$ and o), LAI-induced changes in the simulated turbulent fluxes are more apparent in the summer months and over fully vegetated and residential pixels, where sensible heat flux is significantly increased (up to 57.2 and $86.5 \mathrm{MJ} \mathrm{m}^{-2}$ month $^{-1}$, respectively) and latent heat flux is significantly decreased (up to 65.5 and $97.9 \mathrm{MJ} \mathrm{m}^{-2}$ month $^{-1}$, respectively). This is due to the considerable deceases in the LAI values in summertime which lead to elevations of the canopy resistance and therefore reductions of the transpiration from the vegetation, causing decreases in latent heat fluxes. This in turn partitions the net radiation more into sensible heat fluxes. LAI does not affect fluxes from industrial/commercial pixels with small pervious fractions (Fig. 2p). It is worth mentioning that changes in the turbulent fluxes time series, in particular the latent heat flux decreases in the summer months induced by implementation of satellite-based LAI, are to some extent captured in the simulations with the remote-sensing-based GVF (compare Fig. $2 b$ with $n$ and $c$ with o). This reflects our previous point that GVF controls assigned LAI values to vegetated pixels in the Noah LSM and that realistic presentation of GVF in the modeling framework can enhance LAI inputs in the model when LAI measurements are not available.

Remotely sensed emissivity maps are also utilized to replace the default values in the Noah-UCM simulations, which results in changes in the emissivity values (up to $5.1 \%$ ). However, the new surface parameterization leads to insignificant changes in turbulent fluxes (results now shown). The largest emissivity induced alterations in sensible heat fluxes are seen over industrial and commercial pixels (up to $31.2 \mathrm{MJ} \mathrm{m}^{-2}$ month $^{-1}$ ). Latent heat fluxes are changed most significantly over fully vegetated areas (up to $2.56 \mathrm{MJ} \mathrm{m}^{-2}$ month $^{-1}$ ).

\subsection{Spatial evaluation}

The spatial distributions of newly assigned GVF, ISA, albedo, and LAI are next compared with those based on the Noah-UCM lookup tables. Different urban surface parameterizations, along with their impacts on the simulated maps of turbulent sensible and latent heat fluxes, are presented (Fig. 3; valid at 11:00 LST on 14 April 2011). As expected, during the spring period (April), GVF values are significantly higher when remote sensing products are utilized, due to the irrigation effects which are ignored in the default parameters (Fig. 3a and b). Over fully vegetated and low-intensity residential pixels, where a significant portion of the energy goes into evaporation and transpiration, latent heat flux increases (about 300 and $230 \mathrm{~W} \mathrm{~m}^{-2}$, respectively) and sensible heat fluxes decreases (about 160 and $120 \mathrm{~W} \mathrm{~m}^{-2}$, respectively) are found (Fig. $3 \mathrm{c}$ and d) when utilizing the remote sensing GVF.

The spatial distributions of ISA, or urban fraction, between the remote sensing and default values show similar patterns
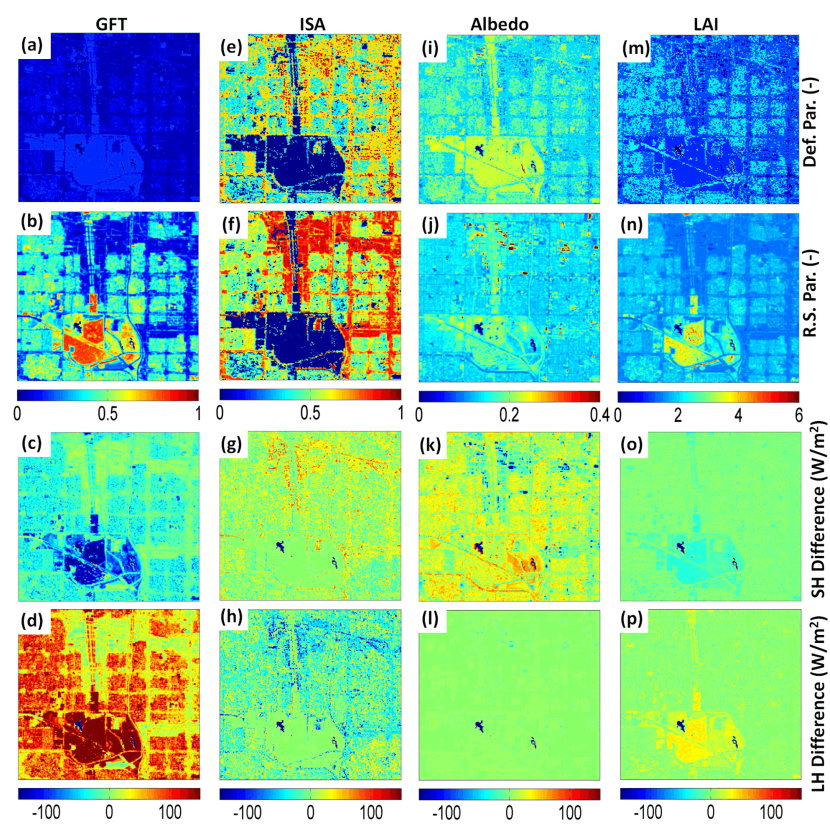

Figure 3. Spatial distributions of GVF, ISA, albedo, and LAI based on Noah-UCM lookup tables (row 1) compared with remotely sensed values (row 2) and simulated difference maps of sensible (row 3) and latent (row 4) heat fluxes using default and remotely sensed urban surface parameters: (c and d) GVF, (g and h) ISA, (k and l) albedo, and (o and p) LAI. Valid at 11:00 LST on 14 April 2011

(Fig. 3e and f). However, industrial/commercial and highintensity residential areas are assigned noticeably higher urban fraction values in the remote-sensing-based maps (compare Fig. 3e with f), which leads to lower latent heat fluxes (bias of up to about $130 \mathrm{~W} \mathrm{~m}^{-2}$ ) and higher sensible (bias of up to about $100 \mathrm{~W} \mathrm{~m}^{-2}$ ) in these pixels (Fig. $3 \mathrm{~g}$ and $\mathrm{h}$ ).

The Noah-UCM parameters, based on lookup tables, underestimate surface albedo values over highly urbanized pixels when compared with remote sensing data (Fig. $3 i$ and $j$ ). In particular, the industrial/commercial buildings with highly reflective rooftops are completely ignored. Over the highly vegetated areas, however, albedo values are slightly overestimated in lookup tables. With the energy budget altered, the newly developed albedo data sets lead to lower NoahUCM-simulated sensible heat fluxes over intensely developed pixels (Fig. 3k). The sensible heat flux differences are only significant over industrial/commercial pixels, which include buildings with bright roofs (up to $\sim 300 \mathrm{~W} \mathrm{~m}^{-2}$ ). The changes in absolute surface albedos do not affect simulated latent heat fluxes as these reflective roofs are located in industrial/commercial areas with negligible pervious surfaces and simulated latent heat flux (Fig. 31).

The remote sensing data detect higher LAI values over all pixel types, particularly over fully vegetated areas, where new LAI values are significantly higher (Fig. $3 \mathrm{~m}$ and $n$ ). By influencing the canopy resistance, these changes redefine 
the spatial distribution of turbulent fluxes (Fig. 3o and p). Over the densely vegetated areas, increases in latent heat flux (up to $50 \mathrm{~W} \mathrm{~m}^{-2}$ ) and decreases in sensible heat flux (up to $35 \mathrm{~W} \mathrm{~m}^{-2}$ ) are found (Fig. 3o and p). It is noteworthy that, as illustrated before (Fig. 3n and o), the most significant influences of LAI alterations are detected in the summer months. Thus, it is not surprising that the turbulent fluxes do not show significant sensitivity to the LAI changes in April.

Remotely sensed emissivity maps, implemented in the Noah-UCM simulations, show minimal effect on the output turbulent fluxes maps (results not shown). Our results (Figs. 2 and 3) agree with previous sensitivity studies performed with the Noah UCM, which indicated high sensitivity of the model to GVF, ISA, albedo, and LAI, and less model sensitivity to emissivity (Loridan et al., 2010; Wang et al., 2011). Loridan et al. (2010) highlighted the critical role of ISA and LAI in the simulations of latent heat flux and albedo role in the sensible heat flux simulations. Investigating the peaks of diurnal turbulent fluxes, Wang et al. (2011) reported that latent heat flux is the most sensitive to the GVF. They also found that emissivity has minimal effects on the model outputs.

\section{Evaluation of Noah-UCM performance}

After initial sensitivity tests, the model performance in reproducing ET and LST fields is evaluated using remotely sensed (independent from derived parameters) and in situ measurements. The comparisons of observed and simulated ET and LST, using different urban surface parameterizations (scenarios 1, 7, 8, and 9 in Table 1), are presented in Figs. 4, 5, and 6.

\subsection{ET simulations}

The temporal variations of ET, simulated by the Noah-UCM model and averaged over fully vegetated pixels, are evaluated against CIMIS-based ET measurements, spanning 2010 and 2011 (Fig. 4). The presented observations are averages over fully vegetated pixels in the study domain, calculated using ET maps based on $\mathrm{ET}_{0}$ measurements from 10 CIMIS stations, landscape coefficients, and inverse-distance weighting (second power; see Sect. 5.2). The model reproduces similar ET behaviors when the default parameters and the second group of remotely sensed parameters (albedo, LAI, and emissivity) are implemented (Fig. 4a and c). The ET differences between observations and the default simulation are minimal in the winter and fall months, due to the limited energy available for ET in those months. Over the warmer months, the observed and modeled ETs show distinct behaviors. CIMIS stations report two peaks: one in the spring and one in the summertime. Simulated ETs, however, illustrate one peak in July. The Noah UCM, using these parameterizations, underestimates ET rates for the most of winter and spring months and overestimates them in the summertime (Fig. 4a and c). Including remotely sensed albedo, LAI, and emissivity does
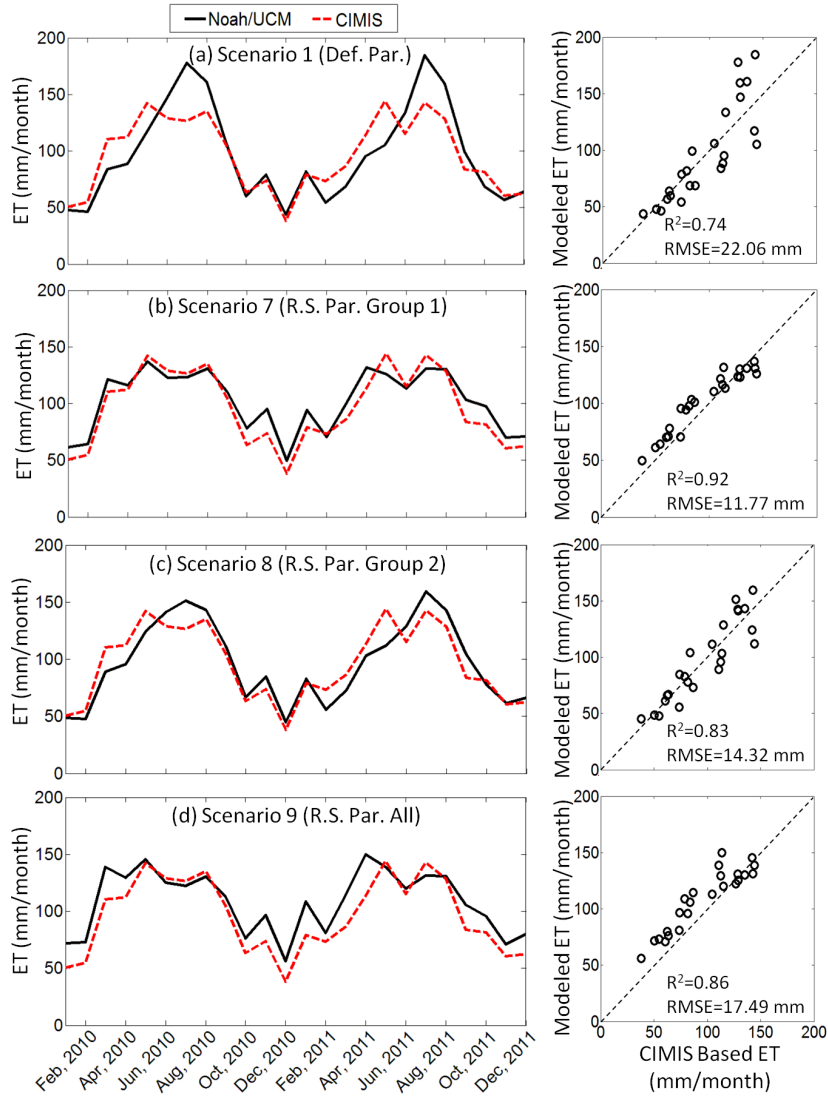

Figure 4. Noah-UCM-simulated cumulative monthly ET, averaged over fully vegetated pixels using different urban surface parameterizations: scenarios (a) 1, (b) 7, (c) 8, and (d) 9 in the Table 1 and their comparisons with CIMIS-based ET measurements spanning 2010 and 2011. Scatter plots of these comparisons are also included (right)

not change the general seasonal pattern deviations of ET (Fig. 4a and c), but it reduces the biases considerably (with $R^{2}=0.83$ and $\mathrm{RMSE}=14.32 \mathrm{~mm} \mathrm{month}^{-1}$ ). We note that model improvement is mostly associated with inclusion of remotely sensed LAI maps in the model since albedo and emissivity have minimal influence on latent heat fluxes from heavily vegetated pixels (see Fig. 2j).

The new GVF and ISA values alter ET seasonal fluctuations significantly in scenario 7 (Fig. 4b). In agreement with CIMIS observations, the model with inclusion of remotely sensed parameters results in significantly higher ET values in the warming months (February-May) and lower ETs in the summertime. With it noted that ISA has minimal effects over the fully vegetated pixels, one explanation for this pattern is that higher green vegetation fraction detected by Landsat in late winter and early spring increases transpiration rates as soon as the required energy is available and lower measured GVFs in the summertime suppress the transpiration rates, resulting in the lower ET values. These 
changes enhance the model performance significantly (with $R^{2}=0.92$ and $\mathrm{RMSE}=11.77 \mathrm{~mm} \mathrm{month}^{-1}$ ).

Including all the measured parameter sets (Fig. 4d) reduces the behavioral disagreements between observed and modeled monthly ET $\left(R^{2}=0.86\right)$. Large biases over the summer months are also reduced. However, ET values are overestimated over the rest of the year (RMSE = $\left.17.49 \mathrm{~mm} \mathrm{month}^{-1}\right)$. Although each newly developed parameter group enhances the model performance in predicting ET, the advantages are countered when all of the parameters are implemented in the model. This is possibly due to the complex interactions between the parameters (e.g., GVF and LAI) in the model structure.

A notable pattern detected by CIMIS data is the drop in ET values over the month of June. The sudden decrease in ET corresponds to the "June gloom" weather pattern in southern California, when onshore flows result in persistent overcast skies with cool temperatures, as well as fog and drizzle in late spring and early summer (NWS, 2011). The June gloom effects are captured in scenarios 7 and 9 (Fig. 4b and d) and not seen in scenarios 1 and 8 (Fig. 4a and c). Since ISA has minimal influence on ET from the fully vegetated pixels and the second group fails to simulate June gloom influence, the improvements in scenarios 7 and 9 in capturing this phenomenon are associated with a more accurate representation of GVF.

\subsection{LST simulations}

In order to further evaluate model performance and examine the impacts of different remote-sensing-based parameter sets, Landsat-based LST measurements are utilized (Figs. 5 and 6). Statistics ( $R^{2}$ and RMSE) are also included to quantify the model performance using different urban surface parameterizations (Fig. 5). The observed LSTs over fully vegetated pixels are estimated with fair accuracy by the default model $\left(R^{2}=0.86\right.$ and $\mathrm{RMSE}=3.21{ }^{\circ} \mathrm{C}$; Fig. 5a). The model performance has almost the same level of accuracy over lowintensity residential areas and is slightly worse $\left(<1^{\circ} \mathrm{C}\right)$ over industrial/commercial pixels (Fig. 5e). Using remote sensing data over fully vegetated and low-intensity residential pixels weakly improves the biases (with $<1{ }^{\circ} \mathrm{C}$ improvement; Fig. 5b-d and f-h). Over industrial/commercial areas, a systematic underestimation of the observed LST is identified $\left(\mathrm{RMSE}=3.96-4.59^{\circ} \mathrm{C}\right.$; Fig. $\left.5 \mathrm{i}-1\right)$ which seems to be persistent after using different remotely sensed parameter sets. We speculate that this underestimation of LST over highly developed areas is due to lack of representation of anthropogenic heating in the current study.

A comparison of LST at 11:00 LST on 14 April 2011 with four simulation cases is also presented (Fig. 6). Alterations due to use of remote sensing products are more noticeable in this spatial examination of the results. Using all the default parameters (scenario 1), observed LST is overestimated over
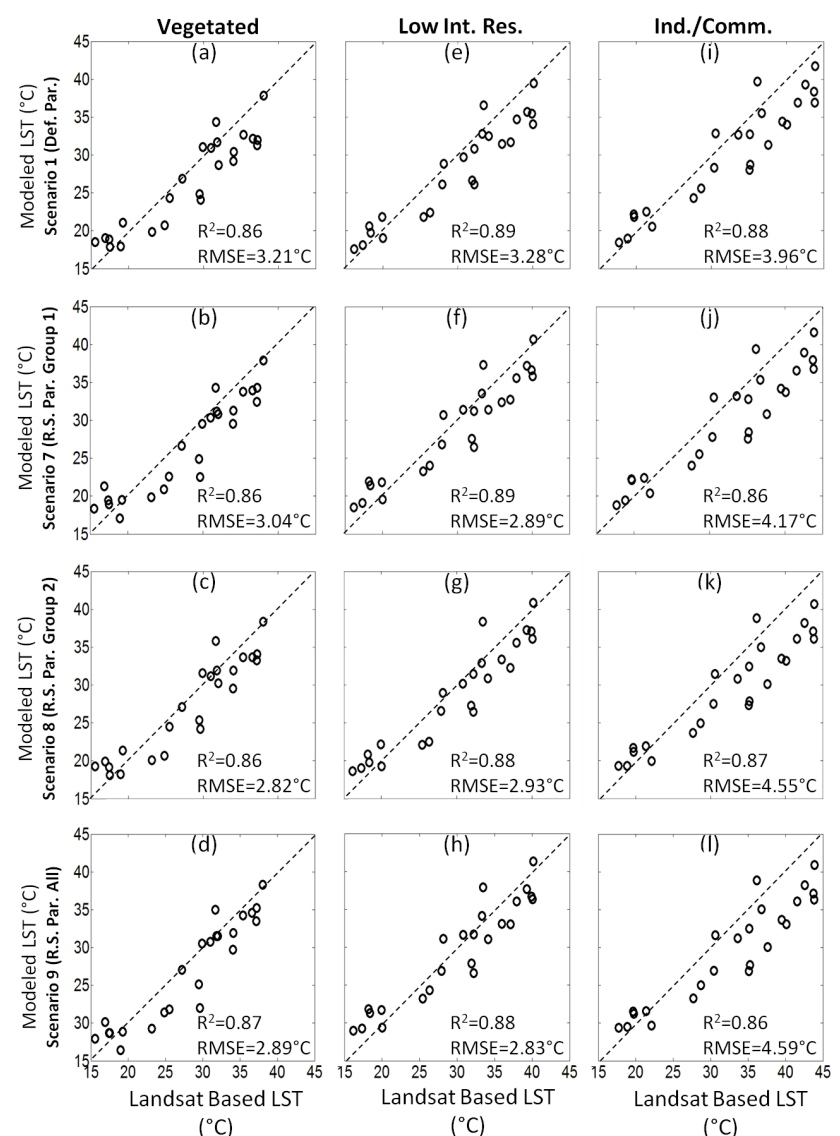

$\left({ }^{\circ} \mathrm{C}\right)$

$\left({ }^{\circ} \mathrm{C}\right)$

Figure 5. Scatter plots of observed (Landsat-based) versus simulated LSTs averaged over different land cover types using different urban surface parameterizations, including scenarios 1 (row 1), 7 (row 2), 8 (row 3), and 9 (row 4) in Table 1.

the heavily vegetated areas and underestimated over highly developed pixels (Fig. 6a and b).

Remotely sensed GVF and ISA (in scenario 7) significantly decrease LSTs over fully vegetated and low-intensity residential pixels and increase temperatures over industrial and commercial areas, resulting in a better match with the observed LST map. The decreased simulated surface temperatures over heavily vegetated areas is due to higher GVF and consequently higher ET rates, which in turn lead to lower sensible heat flux and LSTs (see Fig. 3b). The increased LSTs over highly developed areas is likely due to lower GVF and higher ISA values detected in Landsat imagery compared with the default values, which partition net radiation more into sensible heat flux (see Fig. $3 b$ and f). The noticed changes in LST maps are small, when using remotely sensed albedo, LAI, and emissivity in scenario 8 (compare Fig. 6a with e). Although simulated LSTs over fully vegetated areas are decreased, the observed temperatures are still overestimated (Fig. 6f). The LST decreases in scenario 8 may be explained by evaporative cooling effect of the higher LAI values over heavily vegetated areas (see Fig. 3n). Similar to 

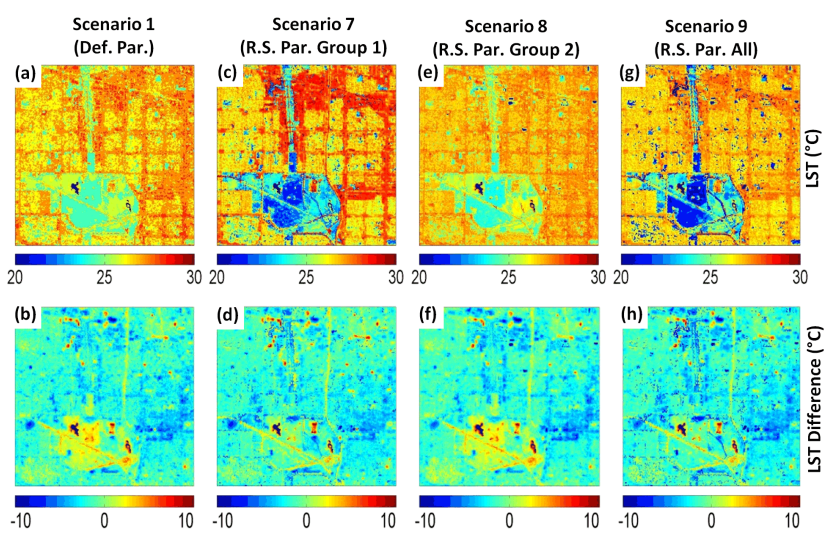

Figure 6. Noah-UCM-simulated LST maps using different urban surface parameterizations: scenarios 1, 7, 8, and 9 from Table 1 (top row) as well as differences between simulated and observed land surface temperature at 1100 LST on 14 April 2011 (bottom row).

scenario 7, considerable GVF-induced LST reductions over fully vegetated areas improve the observed LST estimations in scenario 9 (Fig. 6h). Our assessment indicates that implemented satellite-derived parameter maps, particularly GVF and ISA used in scenarios 7 and 9, enhance the Noah-UCM capability to reproduce the LST differences between fully vegetated pixels and highly developed areas (simulated LST differences of $3.07,6.78,3.48$, and $7.30^{\circ} \mathrm{C}$ for scenarios 1 , 7,8 , and 9 vs. observed LST difference of $11.25^{\circ} \mathrm{C}$ ).

\subsection{Energy and water budget evaluation}

Differences in the simulated energy and water budgets, with different surface parameterizations (scenarios 1, 7, 8, and 9 in the Table 1) are summarized for WY 2011 (Fig. 7). The emissivity induced changes to the energy and water budgets are insignificant and not included. The illustrated radiative and turbulent heat fluxes show that, unlike the longwave radiative fluxes, the simulated available solar radiations are altered considerably using different urban parameter sets (up to $6 \%$ ), particularly over fully vegetated (Fig. 7a) and industrial/commercial pixels (Fig. 7c). These changes are induced by new surface albedo values utilized in scenarios 8 and 9 . It is also observed that most of the incoming radiative energy is dissipated through latent heat fluxes, over heavily vegetated pixels (Fig. 7a and b), and sensible heat fluxes over industrial/commercial areas (Fig. 7c). These turbulent fluxes are also altered when different surface parameterizations are incorporated. Implementing all the remotely sensed parameters (scenario 9), the annual latent heat flux is increased (12\%) over fully vegetated pixels (Fig. 7a), and the annual sensible heat flux is decreased ( $32 \%$ ) over industrial/commercial pixels (Fig. 7c). Ground heat fluxes, however, are insignificant and unchanged.

Water budget terms also show variable behavior using different parameter sets over different land cover types
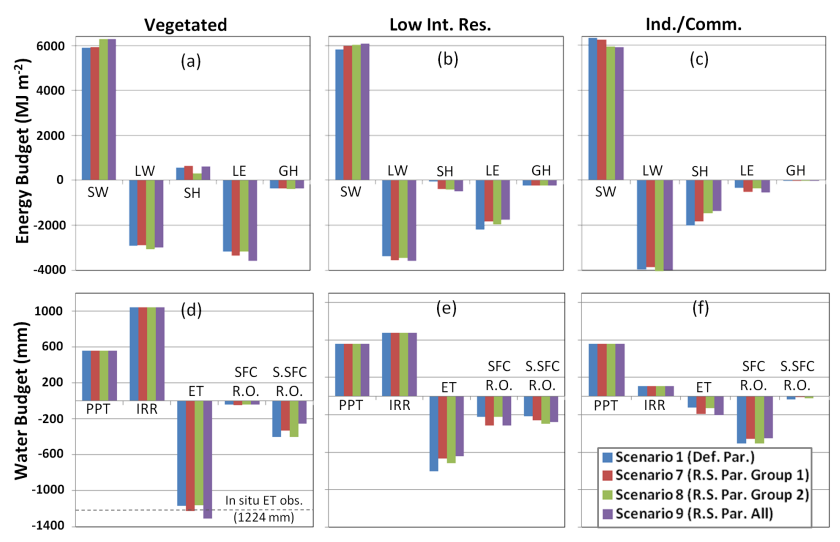

Figure 7. Differences in simulated energy (top) and water (bottom) budgets for WY 2011, using different urban surface parameterization and averaged over different land cover types. Energy budget terms include shortwave radiation (SW) and longwave radiation (LW), as well as sensible (SH), latent (LH), and ground (GH) heat fluxes. Water budget terms include precipitation (PPT), irrigation water (IRR), evapotranspiration (ET), surface runoff (SFC R.O.), and subsurface runoff (S. SFC R.O.).

(Fig. 7d-f). Annual irrigation amounts exceed received precipitations over the pixels with significant vegetation fractions (Fig. 7d and e). This pattern is not rare in semiarid regions (CDWR, 1975; Mini et al., 2014). In these areas, most of incoming water is lost through ET (Fig. 7d and e). Areas with high coverage of impervious surfaces, however, dissipate most of the incoming moisture through surface runoff (Fig. 7f). The alterations in the annual ET rates are, for the most part, due to the changes in the GVF parameterizations (scenarios 7 and 9; Fig. 7d-f). Sub-surface runoff annual rates, on the other hand, are altered using new ISA values (scenarios 7 and 9; Fig. 7e and f). Changes in the annual ET values are as large as 145,156 , and $79.4 \mathrm{~mm}$ over fully vegetated, low-intensity residential, and industrial/commercial pixels, respectively (Fig. 7d-f).

To further verify the capability of Noah UCM to reproduce observed ET quantities, additional evaluation of the model is conducted utilizing ground-based chamber ET measurements in the greater Los Angeles area (Moering, 2011). Instantaneous ET measurements over an irrigated park in the study domain during WY 2011 are converted to daily and then annual ET estimates $(1224 \mathrm{~mm})$ and compared with the simulated ET values over the parks (Fig. 7d). As expected, the observed ET is best reproduced by scenario 7 (bias of $1.47 \mathrm{~mm}$ ) due to more accurate representation of GVF in the model. scenarios 1 (with the default parameters) and 8 underestimate, with biases of 58.65 and $65.32 \mathrm{~mm}$, respectively. Scenario 9, with all the remotely sensed parameters, overestimates the measured ET (with bias of $86.24 \mathrm{~mm}$ ). These shortcomings are likely due to (1) a lack of accurate representation of GVF in the default parameter sets, used in scenarios 1 and 8 ; (2) the uncertainties associated with the estimated 
LAI values utilized in scenarios 8 and 9; and (3) complex interactions between GVF and LAI noted in scenario 9 .

The presented analysis of energy balance (Fig. 7) suggests that GVF, albedo, and LAI play an important role in regulating simulated radiative energy budget and turbulent fluxes, mainly by affecting the available net radiation and transpiration quantities. GVF, ISA, and LAI also alter the study area transpiration and ET values, as well as surface runoff rates.

\section{Conclusions}

In the current work we investigate the utility of a select set of remote-sensing-based surface parameters in the Noah-UCM modeling framework over a highly developed urban area. It was found that remote sensing data show significantly different magnitudes and seasonal patterns of GVF when compared with the default values. The reason for this mismatch is the significant and year-round irrigation in the Los Angeles area which is not accounted for in the default parameter tables. Irrigated landscapes maintain constant greenness rather than a seasonal behavior of greening in the winter/spring and browning in the summer. The noticed differences between the monthly LAI values from default tables and remotely sensed data are also due to complex irrigation patterns. Another factor that contributes to this mismatch is the fact that landscape plantings are quite different from agricultural crops due to their being composed of collections of vegetation species, which is not taken into account in the vegetation parameter tables in the Noah LSM (CDWR, 2000; Vahmani and Hogue, 2013, 2014). There are also considerable deviations between the lookup-table-based ISA, albedo and emissivity maps, and the remotely sensed values. The results of our analysis agree with previous studies which show high sensitivity of the Noah UCM to GVF, ISA, albedo, and LAI, and minimal model sensitivity to emissivity (Loridan et al., 2010; Wang et al., 2011). Our results show that GVF, ISA, and LAI are critical in the simulations of latent and sensible heat flux, and that albedo plays a key role in the sensible heat flux simulations.

Our assessment of the Noah-UCM ET estimation shows that using the default parameters leads to significant errors in the model predictions of monthly ET fields (RMSE = $22.06 \mathrm{~mm} \mathrm{month}^{-1}$ ) over the study domain in Los Angeles. Results show that accurate representation of GVF is critical to reproduce observed ET patterns over vegetated areas in the urban domains. LAI also plays an important role in ET simulations. However, simulations incorporating the remotely sensed GVF values outperform (RMSE = $11.77 \mathrm{~mm} \mathrm{month}^{-1}$ ) simulations with the new LAI estimates $\left(\right.$ RMSE $\left.=14.32 \mathrm{~mm} \mathrm{month}^{-1}\right)$. This could be due to several reasons. First, there are uncertainties associated with the remote-sensing-based LAI retrieval, including nonlinearity of LAI-vegetation index (RSR) relationships (Latifi and Galos, 2010), which do not apply to NDVI-based GVF. Second, more accurate representation of GVF values in the Noah UCM not only improves the assigned LAI values to the vegetated pixels in the model but also enhances other parameters' inputs as well (i.e., albedo, emissivity, and roughness length). Further analysis of the model performance indicates that implemented satellite-derived parameter maps, particularly GVF and ISA, enhance the capability of the Noah UCM to reproduce the LST differences between fully vegetated pixels and highly developed areas (simulated LST differences of 3.07 and $6.78^{\circ} \mathrm{C}$ for scenarios with default and remotely sensed GVF and ISA vs. observed LST difference of $11.25^{\circ} \mathrm{C}$ ).

Our analysis of energy balance suggests that GVF, albedo, and LAI play an important role in regulating simulated radiative energy budget and turbulent fluxes, mainly by affecting the available net radiation and ET quantities. With regard to urban water balance, GVF, ISA, and LAI play a key role in surface hydrologic fluxes, including ET and surface runoff. When compared with in situ observations, Noah UCM shows the capacity to reproduce ET fields with relatively high accuracy (Bias of $1.47 \mathrm{~mm}$ ) when GVF maps are updated using remote sensing data.

In summary, the current study highlights the significant deviations between the spatial distributions and seasonal fluctuations of the default and remotely sensed parameter sets in the Noah UCM. We illustrate that replacing default parameters with the measured values reduces significant biases in model predictions of the surface fluxes within irrigated urban areas. This ultimately has key implications in feedback processes to the atmosphere when the Noah UCM is coupled with the widely used WRF model, which has been increasingly applied over urban areas to examine the exchange of heat, moisture, momentum, or pollutants. Semiarid urban cities, in particular, are receiving much attention in the literature, given their accelerated growth and increasing dependence on external water sources. More accurate representation of both water and energy fluxes in commonly used modeling frameworks is critical for regional resource management as well as predictions of urban processes under future climate conditions. Although this study focuses on the widely used single-layer UCM, we speculate that implementation of the more accurate remote-sensing-based parameters (particularly GVF and ISA) may also enhance performance of the Noah BEP (building effect parameterization; Martilli et al., 2002) which is currently the most sophisticated urban scheme in WRF. In this multilayer UCM a similar approach to the single-layer UCM is used based on an urban fraction (or ISA) parameter that couples the Noah outputs over pervious portion of pixels and UCM outputs over developed surfaces. 
Acknowledgements. Funding for this research was supported by an NSF Hydrologic Sciences Program CAREER grant (no. EAR0846662), a 2012 NASA Earth and Space Science Fellowship (no. NNX12AN63H), and an NSF Water Sustainability and Climate (WSC) grant (no. EAR12040235).

Edited by: P. Gentine

\section{References}

Arnfield, A. J.: Two decades of urban climate research: A review of turbulence, exchanges of energy and water, and the urban heat island, Int. J. Climatol., 23, 1-26, doi:10.1002/joc.859, 2003.

Artis, D. A. and Carnahan, W. H.: Survey of emissivity variability in thermography of urban areas, Remote Sens. Environ., 12, 313329, 1982.

Bauer, M. E., Loeffelholz, B., and Wilson, B.: Estimating and mapping impervious surface area by regression analysis of Landsat imagery, Remote Sensing of Impervious Surfaces, 3-20, Boca Raton, Florida: CRC Press, 2007.

Bornstein, R.: Urban climate models: Nature, limitations, and applications, Meteorol. Atmos. Phys., 38, 185-194, 1987.

Burian, S. J., Stetson, S. W., Han, W., Ching, J., and Byun, D.: High resolution dataset of urban canopy parameters for Houston, Texas, Preprint proceedings, Fifth Symposium on the Urban Environment, Vancouver, BC, Canada, 23-26 August, Am. Meteorol. Soc.: Boston, MA, 2004.

Burian, S. J., Brown, M., McPherson, T. N., Hartman, J., Han, W., Jeyachandran, I., and Rush, J.: Emerging urban databases for meteorological and dispersion, Sixth Symposium on the Urban Environment, Atlanta, GA, 28 January-2 February, Am. Meteorol. Soc.: Boston, MA, Paper 5.2, 2006.

Burian, S. J., Brown, M. J., and Augustus, N.: Development and assessment of the second generation National Building Statistics database, Seventh Symposium on the Urban Environment, San Diego, CA, 10-13 September, Am. Meteorol. Soc.: Boston, MA, Paper 5.4, 2007.

California Department of Water Resources (CDWR): California's ground water, Bulletin 118, Department of Water resources, State of California, 1975.

California Department of Water Resources (CDWR): A guide to estimating irrigation water needs of landscape plantings in California: The landscape coefficient method and WUCOLS III, Department of Water Resources, State of California, 1-150, 2000.

Changnon, S. A. and Huff, F. A.: The urban-related nocturnal rainfall anomaly at St. Louis, J. Climate Appl. Meteorol., 25, 1985-1995, doi:10.1175/15200450(1986)025<1985:TURNRA>2.0.CO;2, 1986.

Changnon, S. A.: Inadvertent weather modification in urban area: Lessons for global climate change, B. Am. Meteorol. Soc., 73, 619-627, doi:10.1175/15200477(1992)073<0619:IWMIUA>2.0.CO;2, 1992.

Chen, F. and Dudhia, J.: Coupling an advanced landsurface/hydrology model with the Penn State/NCAR MM5 modeling system. Part I: model implementation and sensitivity, Mon. Weather Rev., 129, 569-585, 2001.

Chen, F., Mitchell, K., Schaake, J., Xue, Y., Pan, H.-L., Koren, V., Duan, Q. Y., Ek, M., and Betts, A.: Modeling of land-surface evaporation by four schemes and comparison with FIFE observations, J. Geophys. Res., 101, 7251-7268, doi:10.1029/95JD02165, 1996.

Chen, F., Janjic, Z., and Mitchell, K.: Impact of atmospheric surface layer parameterization in the new land-surface scheme of the NCEP mesoscale Eta model, Boundary-Lay. Meteorol., 85, 391-421, doi:10.1023/A:1000531001463, 1997.

Chen, F., Kusaka, H., Tewari, M., Bao, J. W., and Harakuchi, H.: Utilizing the coupled WRF/LSM/urban modeling system with detailed urban classification to simulate the urban heat island phenomena over the Greater Houston area, Paper 9.11, Am. Meteorol. Soc., Fifth Symposium on the Urban Environment, Vancouver, BC, Canada, 2004.

Chen, F., Kusaka, H., Bornstein, R., Ching, J., Grimmond, C. S. B., Grossman-Clarke, S., Loridan, T., Manning, K. W., Martilli, A., Miao, S., Sailor, D., Salamanca, F. P., Taha, H., Tewari, M., Wang, X., Wyszogrodzki, A. A., and Zhang, C.: The integrated WRF/urban modelling system: development, evaluation, and applications to urban environmental problems, Int. J. Climatol., 31, 273-288, doi:10.1002/joc.2158, 2011.

Cheng, F. Y. and Byun, D. W.: Application of High Resolution Land Use and Land Cover Data for Atmospheric Modeling in the Houston-Galveston Metropolitan Area: Part I, Meteorological Simulation Results, Atmos. Environ., 42, 7795-7811, doi:10.1016/j.atmosenv.2008.04.055, 2008.

Cheng, F. Y., Hsu, Y. C., Lin, P. L., and Lin, T. H.: Investigation of the Effects of Different Land Use and Land Cover Patterns on Mesoscale Meteorological Simulations in the Taiwan Area, J. Appl. Meteorol. Climatol., 52, 570-587, doi:10.1175/JAMC-D12-0109.1, 2013.

Ching, J., Brown, M., McPherson, T., Burian, S., Chen, F., Cionco, R., Hanna, A., Hultgren, T., Sailor, D., Taha, H., and Williams, D.: National Urban Database and Access Portal Tool, NUDAPT, B. Am. Meteorol. Soc., 90, 1157-1168, doi:10.1175/2009BAMS2675.1, 2009.

Cotton, W. R. and Pielke, R. A.: Human impacts on weather and climate, Cambridge: Cambridge University Press, 1995.

De Ridder, K., Bertrand, C., Casanova, G., and Lefebvre, W.: Exploring a new method for the retrieval of urban thermophysical properties using thermal infrared remote sensing and deterministic modeling, J. Geophys. Res., 117, D17108, doi:10.1029/2011JD017194, 2012.

Ek, M. B., Mitchell, K. E., Lin, Y., Rogers, E., Grunmann, P., Koren, V., Gayno, G., and Tarpley, J. D.: Implementation of Noah land surface model advances in the National Center for Environmental Prediction operational mesoscale Eta model, J. Geophys. Res., 108, 8851, doi:10.1029/2002JD003296, 2003.

Giannaros, T. M., Melas, D., Daglis, I. A., Keramitsoglou, I., and Kourtidis, K.: Numerical study of the urban heat island over Athens (Greece) with the WRF model, Atmos. Environ., 73, 103-111, doi:10.1016/j.atmosenv.2013.02.055, 2013.

Gutman, G. and Ignatov, A.: Derivation of green vegetation fraction from NOAA/AVHRR for use in numerical weather prediction models, Int. J. Remote Sens., 19, 1533-1543, 1998.

Hanasaki, N., Kanae, S., Oki, T., Masuda, K., Motoya, K., Shirakawa, N., Shen, Y., and Tanaka, K.: An integrated model for the assessment of global water resources - Part 1: Model description and input meteorological forcing, Hydrol. Earth Syst. Sci., 12, 1007-1025, doi:10.5194/hess-12-1007-2008, 2008a. 
Hanasaki, N., Kanae, S., Oki, T., Masuda, K., Motoya, K., Shirakawa, N., Shen, Y., and Tanaka, K.: An integrated model for the assessment of global water resources - Part 2: Applications and assessments, Hydrol. Earth Syst. Sci., 12, 1027-1037, doi:10.5194/hess-12-1027-2008, 2008 b.

Jiang, X., Wiedinmyer, C., Chen, F., Yang, Z. L., and Lo, J. C. F.: Predicted impacts of climate and land use change on surface ozone in the Houston, Texas, area, J. Geophys. Res., 113, D20312, doi:10.1029/2008JD009820, 2008.

Jin, M. and Shepherd J. M.: Inclusion of urban landscape in a climate model - How can satellite data help?, B. Am. Meteorol. Soc., 86, 681-689, doi:10.1175/BAMS-86-5-681, 2005.

Johnson, T. D. and Belitz K.: A remote sensing approach for estimating 1 the location and rate of urban irrigation in semi-arid climates, J. Hydrology, 414-415, 86-98, 2012.

Justice, C. O., Townshend, J. R. G., Vermote, E. F., Masuoka, E., Wolfe, R. E., Saleous, N., Roy, D. P., and Morisette, J. T.: An overview of MODIS land data processing and product status, Remote Sens. Environ., 83, 3-15, 2002.

Kalnay, E. and Cai, M.: Impact of urbanization and land-use change on climate, Nature, 423, 528-531, 2003.

Kusaka, H. and Kimura, F.: Thermal effects of urban canyon structure on the nocturnal heat island:Numerical experiment using a mesoscale model coupled with an urban canopy model, J. Appl. Meteorol., 43, 1899-1910, 2004.

Kusaka, H., Kondo, H., Kikegawa, Y., and Kimura, F.: A simple single-layer urban canopy model for atmospheric models: Comparison with multi-layer and slab models, Boundary-Lay. Meteorol., 101, 329-358, 2001.

Landsberg, H. E.: The urban climate, New York: Academic Press, 1981.

Latifi, H. and Galos, B.: Remote sensing-supported vegetation parameters for regional climate models: a brief review, iForest, 3, 98-101, doi:10.3832/ifor0543-003, 2010.

Li, D. and Bou-Zeid, E.: Quality and Sensitivity of High-Resolution Numerical Simulation of Urban Heat Islands, Environ. Res. Lett., 9, 055001, doi:10.1088/1748-9326/9/5/055001, 2014.

Liang, S.: Narrowband to broadband conversions of land surface albedo: I Algorithms, Remote Sens. Environ., 76, 213-238, 2000.

Loridan, T., Grimmond, C. S. B., Grossman-Clarke, S., Chen, F., Tewari, M., Manning, K., Martilli, A., Kusaka, H., and Best, M.: Trade-offs and responsiveness of the single-layer urban parameterization in WRF: an offline evaluation using the MOSCEM optimization algorithm and field observations, Q. J. R. Meteorol. Soc., 136, 997-1019, doi:10.1002/qj.614, 2010.

Lowry, W.: Urban effects on precipitation amount, Prog. Phys. Geog., 22, 477-520, doi:10.1177/030913339802200403, 1998.

Marshall, C. H., Pielke, R. A., Steyaert, L., and Willard, D.: The impact of anthropogenic land-cover change on the Florida peninsula sea breezes and warm season sensible weather, Mon. Weather Rev., 132, 28-52, doi:10.1175/15200493(2004)132<0028:TIOALC>2.0.CO;2, 2004.

Martilli, A., Clappier, A., and Rotach, M. W.: An urban surface exchange parameterization for mesoscale models, Boundary-Lay. Meteorol., 104, 261-304, 2002.

McPherson, E. G., Simpson, J. R., Xiao, Q., and Wu, C.: Los Angeles 1-million tree canopy cover assessment, Gen. Tech. Rep.
PSW-GTR-207, Albany, CA: US Department of Agriculture, Forest Service, Pacific Southwest Research Station, 52 p., 2008.

Miao, S. and Chen, F.: Formation of horizontal convective rolls in urban areas, Atmos. Res., 89, 298-304, doi:10.1016/j.atmosres.2008.02.013, 2008.

Miao, S., Chen F., LeMone, M. A., Tewari M., Li, Q., and Wang, Y.: An observational and modeling study of characteristics of urban heat island and boundary layer structures in Beijing, J. Appl. Meteorol. Climatol., 48, 484-501, doi:10.1175/2008JAMC1909.1, 2009.

Mini, C., Hogue, T. S., and Pincetl, S.: Estimation of Residential Outdoor Water Use in Los Angeles, California, Landscape Urban Plan., 127, 124-135, doi:10.1016/j.landurbplan.2014.04.007, 2014.

Moering, D. C.: A comparative study of evapotranspiration rates between irrigated and non-irrigated parks in Los Angeles, M.S. thesis, Dep. of Civil and Env. Eng., University of California Los Angeles, Los Angeles, California, 2011.

National Oceanographic and Atmospheric Administration-Coastal Services Center (NOAA-CSC): Southern California 2000-Era Land Cover/Land Use, LANDSAT-TM, 10m, NOAA-CSC, Charleston, SC, 2003.

National Weather Service (NWS): Jet Stream - The Marine Layer, NOAA National Weather Service, available at: http://www.srh. noaa.gov/jetstream/ocean/marine.htm (last access: 24 February 2013), 2011.

Niyogi, D., Holt, T., Zhong, S., Pyle, P. C., and Basara, J.: Urban and land surface effects on the 30 July 2003 mesoscale convective system event observed in the Southern Great Plains, J. Geophys. Res., 111, D19107, doi:10.1029/2005JD006746, 2006.

Pielke, R. A. Sr., Marland, G., Betts, R. A., Chase, T. N., Eastman, J. L., Niles, J. O., Niyogi, D., and Running, S.: The influence of land-use change and landscape dynamics on the climate system: Relevance to climate change policy beyond the radiative effect of greenhouse gases, Phil. Trans. R. Soc. London A, 360, 17051719, 2002.

Pokhrel, Y., Hanasaki, N., Koirala, S., Cho, J., Kim, H., Yeh, P. J.-F., Kanae, S., and Oki, T.: Incorporating anthropogenic water regulation modules into a land surface model, J. Hydrometeorol., 13, 255-269, doi:10.1175/JHM-D-11-013.1, 2012.

Schaaf, C. B., Gao, F., Strahler, A. H., Lucht, W., Li, X. W., Tsang, T., Strugnell, N. C., Zhang, X. Y., Jin, Y. F., Muller, J. P., Lewis, P., Barnsley, M., Hobson, P., Disney, M., Roberts, G., Dunderdale, M., Doll, C., d'Entremont, R. P., Hu, B. X., Liang, S. L., Privette, J. L., and Roy, D.: First operational BRDF, albedo nadir reflectance products from MODIS, Remote Sens. Environ., 83, 135-148, 2002.

Shuai, Y., Schaaf, C. B., Strahler, A. H., Liu, J., and Jiao, Z.: Quality assessment of BRDF/albedo retrievals in MODIS operational system, Geophys. Res. Lett., 35, L05407, doi:10.1029/2007GL032568, 2008.

Shuai, Y., Masek, J. G., Gao, F., and Schaaf, C. B.: An algorithm for the retrieval of 30-m snow-free albedo from Landsat surface reflectance and MODIS BRDF, Remote Sens. Environ., 115, 2204 2216, doi:10.1016/j.rse.2011.04.019, 2011.

Sobrino, J. A. and Raissouni, N.: Toward remote sensing methods for land cover dynamic monitoring: Application to Morocco, Int. J. Remote Sens., 21, 353-366, doi:10.1080/014311600210876, 2000 . 
Sobrino, J. A., Raissouni, N., and Li, Z. L.: A comparative study of land surface emissivity retrieval from NOAA data, Remote Sens. Environ., 75, 256-266, 2001.

Song, M. and Civco, D. L.: A knowledge-based approach for reducing cloud and shadow, Proceedings of the American Society of Photogrammetry and Remote Sensing annual convention, Washington, DC: Am. Soc. Photogramm. Remote Sens., 7 p., 2002.

State of California Department of Water Resources (SCDWR): California irrigation management information system, Sacramento, CA: State of California Department of Water Resources, available at: http://www.water.ca.gov/ (last access: December 2013), 2009.

Stathopoulou, M. and Cartalis, C.: Daytime urban heat islands from Landsat ETM+ and Corine land cover data: An application to major cities in Greece, Sol. Energy, 81, 358-368, doi:10.1016/j.solener.2006.06.014, 2007.

Stathopoulou, M., Cartalis, C., and Petrakis, M.: Integrating Corine Land Cover data and Landsat TM for surface emissivity definition: application to the urban area of Athens, Greece, Int. J. Remote Sens., 28, 3291-3304, doi:10.1080/01431160600993421, 2007.

Stenberg, P., Rautiainen, M., Manninen, T., Voipio, P., and Smolander, H.: Reduced simple ratio better than NDVI for estimating LAI in Finnish pine and spruce stands, Silva Fennica, 38, 3-14, 2004.

Taha, H.: Meso-urban meteorological and photochemical modeling of heat island mitigation, Atmos. Environ., 42, 8795-8809, doi:10.1016/j.atmosenv.2008.06.036, 2008.

Taha, H., Douglas, S., and Haney, J.: Mesoscale meteorological and air quality impacts of increased urban albedo and vegetation, Energ. Buildings, 25, 169-177, doi:10.1016/S03787788(96)01006-7, 1997.

Tan, M. and Li, X.: Integrated assessment of the cool island intensity of green spaces in the mega city of Beijing, Int. J. Remote Sens., 34, 3028-3043, doi:10.1080/01431161.2012.757377, 2013.
Tewari, M., Kusaka, H., Chen, F., Coirier, W. J., Kim, S., Wyszogrodzki, A., and Warner, T. T.: Impact of coupling a microscale computational fluid dynamics model with a mesoscale model on urban scale contaminant transport and dispersion, Atmos. Res., 96, 656-664, doi:10.1016/j.atmosres.2010.01.006, 2010.

US Census: US Census Bureau Releases Data on Population Distribution and Change in the US Based on Analysis of 2010 Census Results, US Census Bureau, 24 March 2011.

Vahmani, P. and Hogue, T. S.: Modelling and analysis of the impact of urban irrigation on land surface fluxes in the Los Angeles metropolitan area, Climate and Land Surface Changes in Hydrology Proceedings of H01, IAHS-IAPSO-IASPEI Assembly, Gothenburg, Sweden, July 2013, IAHS Publ. 359, 2013.

Vahmani, P. and Hogue, T. S.: Incorporating an Urban Irrigation Module into the Noah Land Surface Model Coupled with an Urban Canopy Model, J. Hydrometeorol., 15, 1440-1456, doi:10.1175/JHM-D-13-0121.1, 2014.

Van Wevenberg, K., De Ridder, K., and Van Rompaey, A.: Modeling the contribution of the Brussels heat island to a long temperature time series, J. Appl. Meteorol. Climatol., 47, 976E990, doi:10.1175/2007JAMC1482.1, 2008.

Wang, X. M., Chen, F., Wu, Z. Y., Zhang, M. G., Tewari, M., Guenther, A., and Wiedinmyer, C.: Impacts of weather conditions modified by urban expansion on surface ozone: comparison between the Pearl River Delta and Yangtze River Delta regions, Adv. Atmos. Sci., 26, 962-972, doi:10.1007/s00376-009-80012, 2009.

Wang, Z. H., Bou-Zeid, E., Au, S. K., and Smith, J. A.: Analyzing the sensitivity of WRF's single-layer urban canopy model to parameter uncertainty using advanced Monte Carlo simulation, J. Appl. Meteor. Climatol., 50, 1795-1814, doi:10.1175/2011JAMC2685.1, 2011.

Wei-guang, M., Yan-xia, Z., Jiang-nan, L., Wen-shi, L., Guangfeng, D., and Hao-rui, L.: Application of WRF/UCM in the simulation of a heat wave event and urban heat island around Guangzhou, J. Trop. Meteorol., 3, 257-267, doi:10.3969/j.issn.1006-8775.2011.03.007, 2011. 